\title{
The Making of a Digital (Master)Piece
}

\author{
Rachel Ara \\ Thames-Side Studios \\ London SE18, UK \\ rachel@fluxit.co.uk
}

\begin{abstract}
This presentation is a forthright insight into the development and completion of digital artwork; This Much I'm Worth (The self-evaluating artwork) from prototype to large scale finished piece. This Much I'm Worth continually assesses and displays its sale price governed by a complex set of algorithms called "The Endorsers". Raising questions about values and who apportions them; is it clear how we, as a society, value objects or even people or are those systems really hidden? This Much I'm Worth won the Aesthetica Prize in 2016 and since then the artist has been working on a larger scale spectacular version of the piece in full neon. Over 3 metres wide, the new piece combines 71 pieces of neon controlled, via recycled server room equipment, by the endorsers, the internet of things and other technologies. This Much I'm Worth is part of a wider body of work that addresses feminist issues, conspiracies of silence and misinformation. The final version of the piece has been a challenging and formidable project made all the more complex by the artist's own ambition to work with only women experts in fields dominated by men. The talk will also touch upon issues related to the making around: outsourcing skills, data-mining, methodologies and alternative technologies as well as practical issues of funding, documentation and ongoing algorithmic support of a digital project.
\end{abstract}

Digital art. Feminist. Hybrid art. Conceptual. Misinformation. Socipolitical. Neon. Algorithms. Contemporary art.

\section{INTRODUCTION}

\subsection{Background of Artist}

I worked in the IT industry for nearly 30 years mainly as a programmer, analyst and later as a consultant designing systems ranging from large scale mainframe implementations to apps across a range of industries. During this time I completed a Fine Art degree at Goldsmiths in the 1990s and trained as a cabinet maker in 2012. In 2013 I started my full time practice as an artist.

My work tends to be nonconformist with a sociopolitical edge that often incorporates humour and irony with feminist \& queer concerns. I'm interested in the conspiracy of silence, hidden agendas and their repercussions, especially in terms of the normalisation of violence against women in our culture. I don't define myself as a digital artist - I'm driven by the concept not the technology which then leads me to build the work in whatever material is relevant for the project. This has led me to work in and often combine a diverse range of materials from wood, metals, $16 \mathrm{~mm}$ film through to programming and more lately Virtual Reality (VR). Making and understanding the technologies is an important part of my practice and necessary to building and/or having the necessary control over the development of the work.

\subsection{Overview of Paper}

This paper charts the development of a complex hybrid artwork through the perspective of the artist who made it.

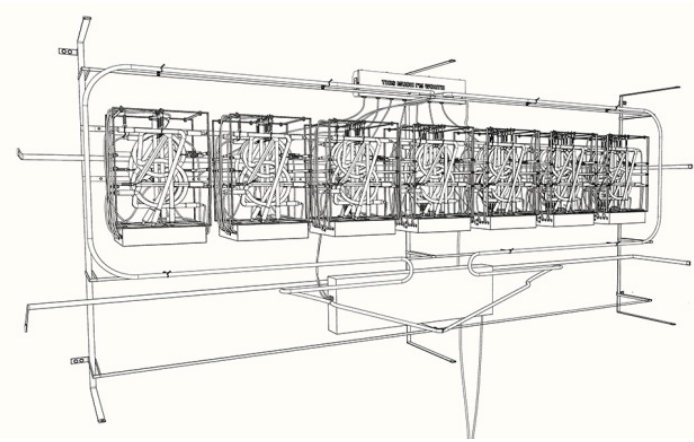

Figure 1: Early CAD drawing of This Much I'm Worth (Full version) by Rachel Ara (C) Rachel Ara 2016

In section 1, l'll present the concept behind the work and discuss some of the philosophical aspects. In the following section l'll discuss aspects of making the prototype and in the third section construction of the final piece. 
To help understand the paper and the way it is presented here are a few disclaimers;

(i) I am not a writer, I am a visual artist.

(ii) I prefer lists to sentences.

(iii) My work is based on practical experiences and those that have been shared with me, rather than through reading journals and publications.

(iv) Many written texts and references have little relevance to me or my experience as a queer woman. (Most referenced publications are still dominated by white / male / heterosexual authors.)

(v) I use generalisations often as a useful rhetorical device. Not all my generalisations are supported by "hard facts" as it is often difficult to substantiate facts surrounding many issues faced by women as they are often ignored and unpublished.

(vi) As an artist I hope this paper raises more questions than answers and provokes further discourse.

\section{THE CONCEPT}

\subsection{My View}

The idea is the easy part. I find my ideas come in "default time" - this is a term I use to describe my state of mind when I'm doing repetitive or familiar tasks. It could be walking, washing up, or making stuff in the workshop. I often get my best ideas at lectures; because of my ADD I rarely listen to what is being said so I find this a very safe space to have my own thoughts.

For this project the idea of creating a functional work of art, which could calculate its own value, came out of many concerns I had around the value system in the art market and how I was noticing large discrepancies between genders. The Guerrilla Girls have recently demonstrated how little shift there has been in last 30 years (Guerrilla Girls 2017). It also tapped into concerns I had around values being placed upon women; traded as commodities for sex or slavery. It also referenced my experiences working in the IT industry where the huge gender pay gaps continue today. In the US it's reported that the gender gap for programmers is still 28\% (FT 2017). I think this may be a generous figure. Over the period I worked in IT I had access to personnel data and unofficially ran programmes to look at the gender pay gap which was at times more than double particularly within the city and consultancies. When I subtly questioned the above with management I was met with such responses "well, he's got a family to support" and "don't rock the boat", with a clear indication that the issues was known but ignored.
It was quite a shock to move from the IT industry, a place where I expected gender discrimination, to the art world that presents itself as more liberal and alternative only to find gender discrimination was thriving. In a sense it's actually worse as here the market is completely unregulated.

\subsection{The Critics View}

Below is an extract from the Aesthetica Anthology written by the critic Dr Sophia Kosmaoglou (2017).

\begin{abstract}
"Rachel Ara's This Much I'm Worth is an artwork that displays its own price. The work quantifies deposits of cultural and social capital and converts them into a single number, a price indicating the amount of financial capital contained within the work, and by extension, Ara's value as an artist. The work functions literally, to address the way that value in the form of cultural capital is bestowed in the art world. But it functions on many other levels as well; it's a tautology (like Robert Morris' Box with the Sound of Its Own Making or Josef Kosuth's Five Words in Red Neon) and an ironic gesture (like Morris' Statement of Aesthetic Withdrawal or UBERMORGEN's Google Will Eat Itself). By flaunting its commodity status, the work fulfils Boris Groys' criteria for critical art, because it "tries to reflect explicitly on its own character as a commodity" (like Mazoni's Artist's Shit or Kristin Luke's The Air Inn Venice). By usurping authority, the work also challenges our unconditional reliance on technology. And by fetishizing technology, it questions our romance with machines."
\end{abstract}

\subsection{Working Ideas}

As I'm working on one project new ideas materialise. Fraught (Because Life Isn't Pure, Simple, Silent, Honest and Absolute) 2015, is an example. This was an outcome of analysis I was doing on the pricing of work by key artists in the Royal Academy (RA) Summer Show. I was collating data to see how certain factors such as gender or size were affecting the price of artworks. Fraught was a direct response to a piece of work, a grey triangle (very beautiful and sublime) by Alan Charlton that was priced at $£ 60,000$. The disparity between male and female work became more obvious as I collated the information. I replicated the exact work in the studio and subverted it by kerfing (bending) the top of the triangle.

I did submit the work to the RA last year, but they did not accept it. 


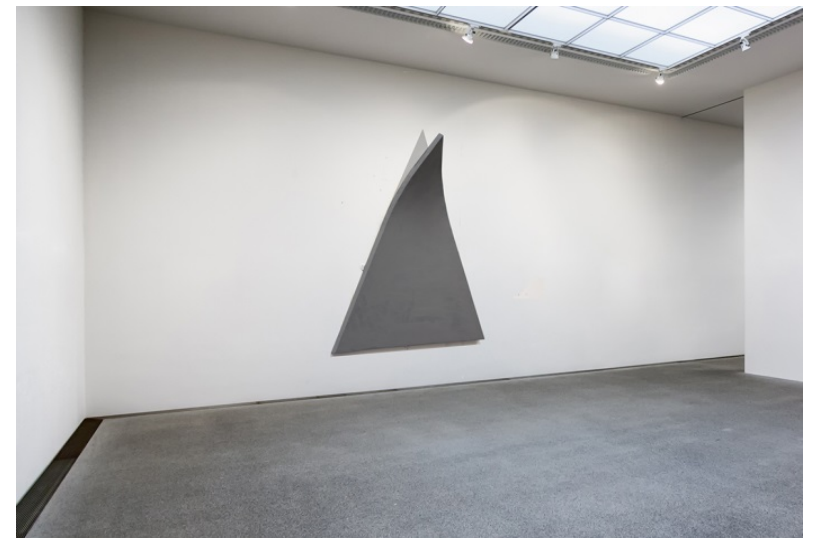

Figure 2: Fraught (because life isn't Pure, Simple, Honest and Absolute) by Rachel Ara (C) Rachel Ara 2015

Fraught is showing at Queering Minimalism, in Newcastle, summer 2017.

\section{THE PROTOTYPE}

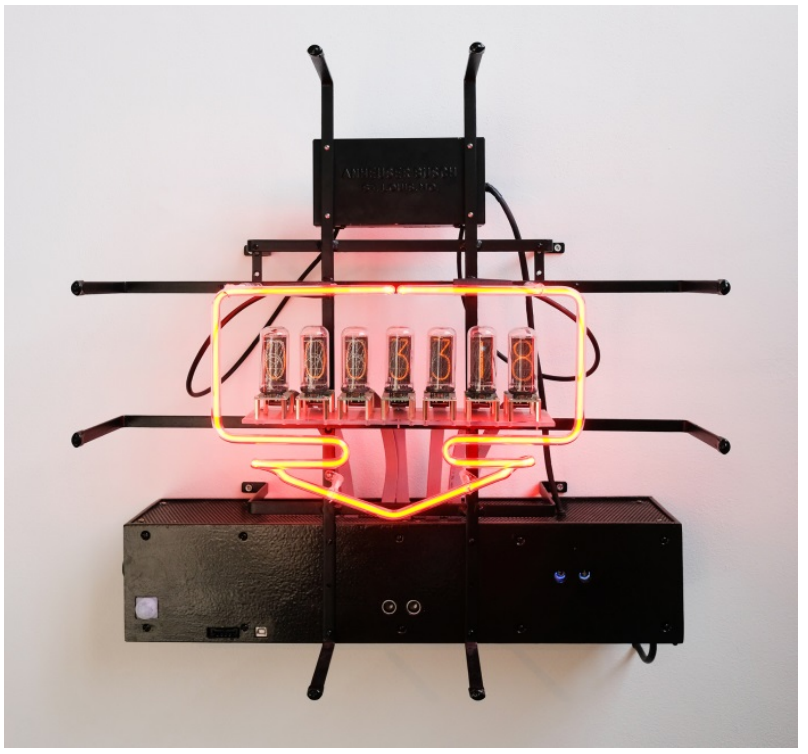

Figure 3: This Much I'm Worth (Prototype) @ Jim Poyner Photography 2016

\subsection{Making}

I work with materials and methods, whether it's welding or programming because they are an integral part of my process. I have to have a deep understanding of the materials in order to build (sculpt) with them. As you understand and familiarise yourself things change and develop and this resonates in the finished work and gives it more depth.

I see code as a modern day paintbrush. You can't expect to pick up some paint and have the skill to immediately translate the image you have in your head? You need to understand how the material behaves. Maybe in today's society artists do want a quick return, a quick route to success. But these shortcuts produce paintings that lack that knowledge and digital works that exploit technology and have no deeper understanding.

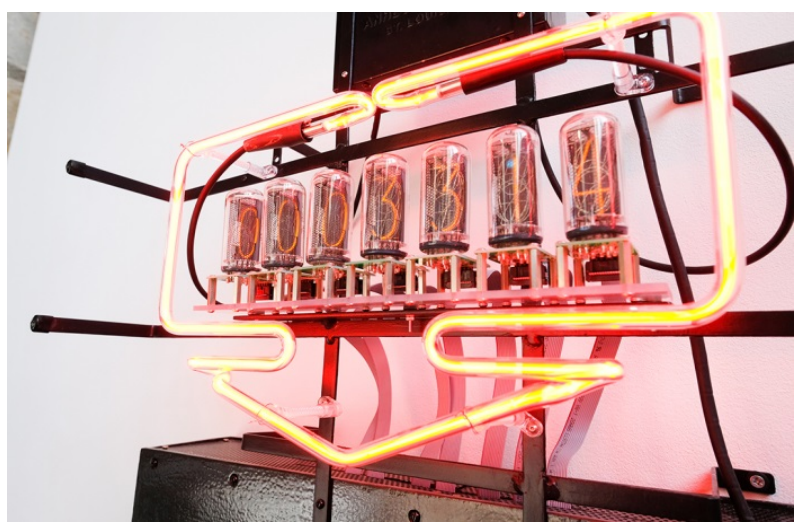

Figure 4: This Much I'm Worth (Prototype) by Rachel Ara (C Jim Poyner Photography 2016

\subsection{Form and Materials}

For this work the starting point was a decision it should be wall mounted in a traditional manner and that I wanted to use nixie tubes to display the value. These were originally designed to be used in old numerical displays.

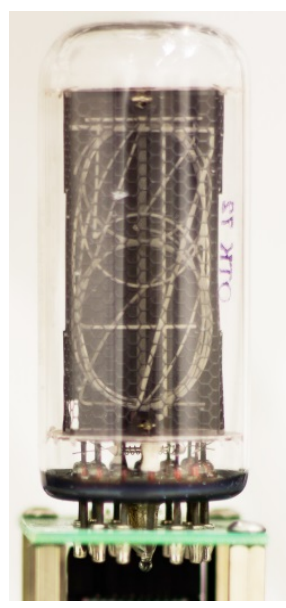

Figure 5: Nixie tube on prototype artwork (IN-18) (C) Rachel Ara 2014

The nixies have their own beauty and reference the calculating machines of the 1950s, if not earlier. The ones I used (IN-18) come from the Ukraine (via EBay). When I was a child I remembered seeing them being used in the countdown sequence of The Six Million Dollar Man. After that the size became relative. I used red neon as a direct reference to the sex trade and to values placed on women. The large red arrow refers to the signage indicating a woman is for sale, putting a price on the woman's head. I investigated how external neon signs were constructed and used that as a basis for the build. The black box containing the 
electronics is a more obvious reference. The sculpture looks like a found object but every part was considered and built from scratch. I like the fact that all the components came from disparate locations, because this devaluing of women is a universal problem. The transformers came from America, the nixies Ukraine, most of the electronics from China, and the frames were fabricated in the UK.

\subsection{Internal Electronics}

The internal electronics are located in the "black box" under the lights. They contain:

- Arduino Mega (Main controller)

- WIFI Shield (Internet access \& GPS)

- Nixie PCB Board (Nixie light controller)

- Temperature Sensor

- Ultrasonic Sensor (Sensing viewer activity)

- PIR Sensor (Sensing viewer activity)

- SD Card Holder (For backup)

- USB Port (Troubleshooting and upgrade)

- 3 LEDs (Troubleshooting and calibration)

- Rotary Switch (12 mode settings)

The Arduino Mega has been programmed with nearly 3000 lines of code. It collects the value of the work from the Internet of Things (IOT) where it is posted nightly by The Endorsers. The value is then passed to the nixie PCB which displays the correct value on the nixie tubes. The Arduino will also collate data from the sensors and pass that back to the IOT to be used in the nightly analysis.

Algorithms run nightly to derive the value for that day. In a gallery setting the value can fluctuate by up to $2 \%$ either way to encourage engagement from the audience. If motion sensors don't detect movement the value slowly drops, if someone approaches the work it increases but not in an obvious way. People are intrigued by how it works or if and how they can affect the price.

The rotary switch (sourced from an old radio) has 12 settings. These invoke different algorithms that are used for troubleshooting, gallery installation and calibration. Error and status codes are displayed using the nixie lights. Alternatively, a computer could be plugged into the USB port for troubleshooting. The modes are defines as follows:

- $01-$ Internet access + active sensors

- 02 - Internet access only

- 03 - SD card + active sensors (no internet)

- 04 - SD Card (no internet)

- 05 - Display fixed value (hardcoded)

- 06 - Nixie light tests and calibration

- 07 - PIR sensor tests and calibration

- 08 - Ultrasonic sensor tests and calibration
- 09 - Temperature display

- 10 - SD card tests

- 11 - Internet connection and ping tests

- 12 - Shutdown artwork

The work can run from an SD card if there is no internet access in the gallery.

\subsection{Coding the Endorsers}

I named the set of algorithms that apportion the value as "The Endorsers" as this reflects the structure of the art world and the endorsements required to progress thought it. The Endorsers are at the heart of the project conceptually and functionally. Should I ever divulge how they work? Should they be open-source? The art world and the banking worlds certainly aren't, so in keeping with the concept I will just summarise how they work.

The endorsers interrogate different variants that affect the value of the artwork. Much of the known values are derived from the artist's provenance. For example, one endorser will interrogate the effect that gender has on the value, another sexuality, another racial profile. Other endorsers will interrogate the "chatter" on social media networks about the artist or the work. Some value will be derived from the work's exhibition history; some will be aligned with inflation, the stock market, and so on. There is always the initial value derived from the material cost and labour. Labour values depend on gender and other variants.

The endorsers also tweet the new value each night and email a copy of the value file to the gallery as a backup for the SD card.

Do the endorsers even have to exist for the artwork to work?

\subsection{The Coded Gaze}

Of course, the endorsers can never be truly comprehensive - and even they are imbued with prejudice handed down from the data collated from social media and various other sources.

If you're not using your own data sets you are reliant on external data which brings into question inherent biases. For example, the Office for National Statistic's data for Domestic Violence (DV) crimes masks the extent of DV by up to $60 \%$ as incidents per victim are capped at 5. (DT 2015). They have also chosen not to record the gender of the victim meaning there are no official statistics on the number of DV crimes against women. A problem that results in the deaths of 2 women per week in the UK (Refuge 2017) or 3 women a day in the US (NNEDV 2017). 


\subsection{Documentation and Maintenance}

If I was producing a product one would expect detailed documentation and a maintenance contract would be required to support the software.

For the prototype, I produced a 47 page manual detailing all the components, internal electronics and internal programming, a two page quick guide and a troubleshooting guide for the installation and running in a gallery. Partly for my own purpose as I know when I get engrossed in the next project I'll start to forget what I did on this one. But where does the responsibility of the artist end?

The work will be for sale but the owner will not own the algorithm, just the facility to collect the value from the Internet of Things.

\section{THE (MASTER)PIECE}

Note: The finished work will be show at Anise Gallery, London, SE1, in a show called "Controlled Realities", June - July 2017.

\subsection{Why Larger?}

Winning the Aesthetica Art Prize in 2016 gave me the funds to build a larger version. The new piece is on a much larger scale responding to the expectation of spectacle. Nicholas Serota proposed that a successful artist should "not simply make small scale works but be capable of making really major statements". This work is about testing that assumption. It's about being taken seriously, creating an impact and it's a crack at the machismo and the art institutions desire for large scale sculpture. I wanted to see if its size would matter. Does it create more chatter on the internet, for the algorithms to pick up and affect the price?

I want the final piece to have an over-engineered (Heath Robinson) aesthetic. If something looks complicated there is a tendency to back off and "trust it".

\subsection{Build Differences from the Prototype}

- The new work is over $600 \%$ larger.

- The sensors from the prototype are replaced with IP cameras - a more sophisticated way of monitoring.

- $\quad$ The Arduino is replaced with a window 7 laptop.

- The nixie PCB board is replaced with 10 managed PDUs, a managed network switch and UPS.

- Each nixie tube is replaced with 10 pieces of neon and 10 transformers.
- The black box is replaced with a new welded box constructed from old server cabinets.

- There are over a 1000 components as part of the assembly.

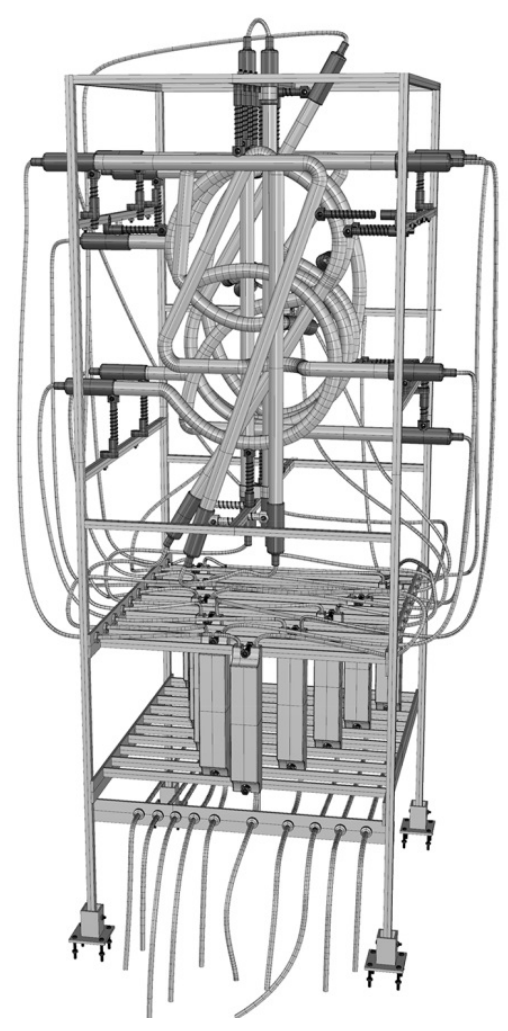

Figure 6: $C A D$ drawing of a neon nixie digit in a cage (C) Rachel Ara 2017

It was quite a formidable task to build. Soldering was replaced with welding - a new skill l'd picked up on YouTube and the London Sculpture Workshop (LSW) who are on-site at my studio complex.

\subsection{Animation System}

I wanted to keep the nixie tubes as the method of display but because they are limited in scale to a around $22 \mathrm{~cm}$ tall I needed to construct my own tubes and decided to do this in neon. This involved 70 pieces of neon, 10 for each digit, and a system to control them. In the previous prototype I used a circuit board that was designed for nixie clocks. The electronics for this would be quite different as it was dealing with cold cathode tubes as opposed to neon. I had concerns that the neon, which runs at $2000 \mathrm{~V}$ compared to the nixes at $170 \mathrm{~V}$ could potentially be dangerous as I'm not an expert. I contacted a company in USA who had done similar animation systems to this, to ask them if they would work with me. Initially they were enthusiastic about the project and I sent over the plans but after exchanging what I would describe as a few healthy emails I received an email saying that they didn't 
want to work with me and would not give me a reason. It left me wondering if it was the mention of queer or feminist in the text that had caused such an adverse reaction. It wouldn't be the first time.

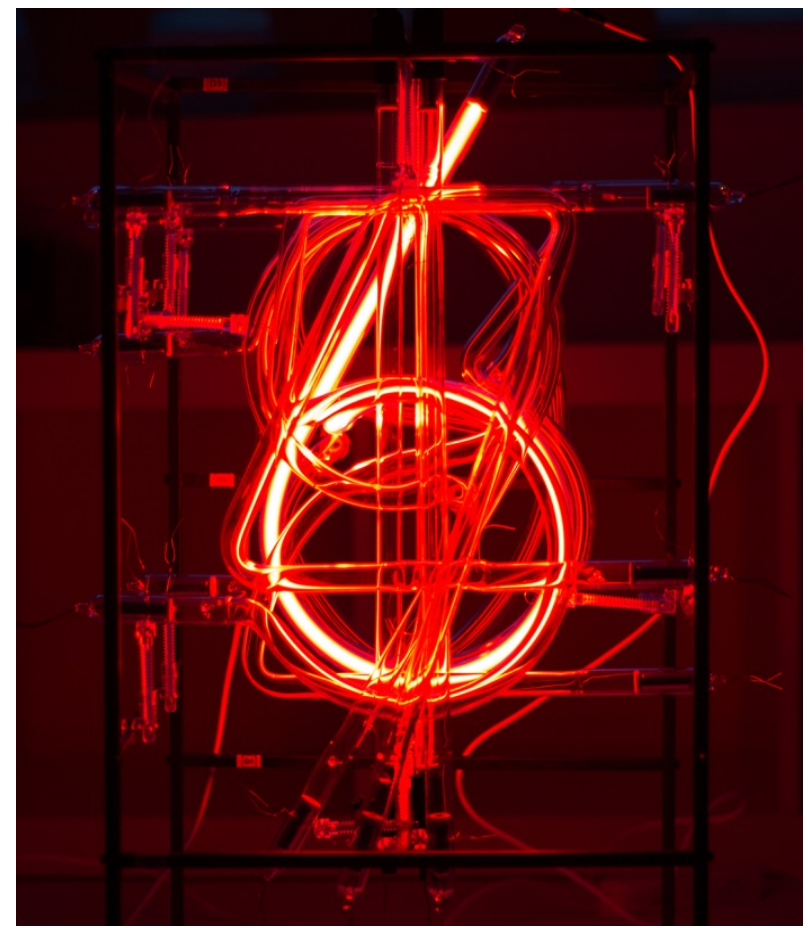

Figure 7: Testing neon nixie digits in the studio @ Ara 2017

Whatever their reasons I decided it would be more interesting to work with women specialists from then on.

I will detail the difficulties I had sourcing women in the next section but this was the solution for animating the neon.

How I arrived at the solution was by remembering the times when I used to make coding errors and the programmes would go into infinite loops. Sometimes the only way to resolve this would be to reboot the server remotely. This was done by issuing commands via a managed PDU (Power Distribution Unit). So I thought I could apply this solution to the neon by individually plugging all the neon into a batch of PDUs. Back on eBay and Gumtree I found lots of companies that were getting rid of redundant server room equipment, so I brought a batch of used managed PDUs and devised a program to control 10 of these that would in turn control the 70 pieces of neon.

\subsection{Women Only}

Finding women to work on the project was the most frustrating but in turn became a significant part of the process. For the neon I was lucky. I had attended a course a couple of years back, learning to blow neon for the prototype where I met Julie
Bickerstaff from Neonunity-Nenocraft. Coincidently she had a shared interest in nixie tubes and was happy to come on board as the neon blower. l've not come across another women neon blower since.

Finding an electrician/engineer proved to be a lot more complicated. According to statistics $1 \%$ of electricians are female. I began by putting advertisements on forums asking for women electricians, but the response was not helpful. Comments like "You're being sexist", "I'll turn up in high heels" and pages full of "This comment has been removed by the moderator" started to appear. It seemed like the male world of electricians felt its dominance threatened. I then turned to universities and WES (Women's Engineer Society), who were very helpful, but with no practical outcome. It was an eye opener how dominant men are in these professions. I knew when I worked in IT that it could be a hostile environment to work in and watched the decline of women in my industry.

When it came to the welding I didn't want to go through the experience I had trying to find a woman electrician so I decided to do it myself.

\subsection{Neon Nixie Lights}

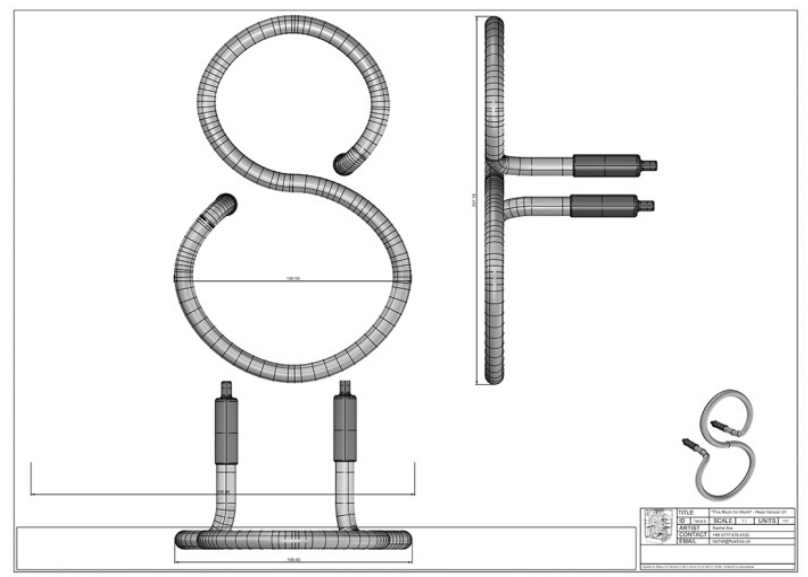

Figure 8: $C A D$ layouts for neon maker by Rachel Ara $(\subset$ Rachel Ara 2016

The neon nixie tubes, possibly the first realisation of nixie tubes in neon, were based on the anatomy of the IN-18 tube that I used in the prototype. They fit within a $90 \times 36 \times 33 \mathrm{~cm}$ metal cage. I designed the neon nixies using Rhino CAD software and simulated the light using VRAY for RHINO so I could see that the stacked digits were functioning correctly. From Rhino I produced the precise technical drawings for the neon maker to work from. She did an amazing job - the neon is exact to the drawings.

When I was building the cages to house the stacked neon digits and wiring, I noticed that if I 
placed the neon pieces too close I get this wonderful electrical interference that could temporarily cause confusion to the reading. I thought this was quite poignant as a small error in coding can often led to significant consequences and decided to leave this in the work. These are the nuances that you get when you build your own work.

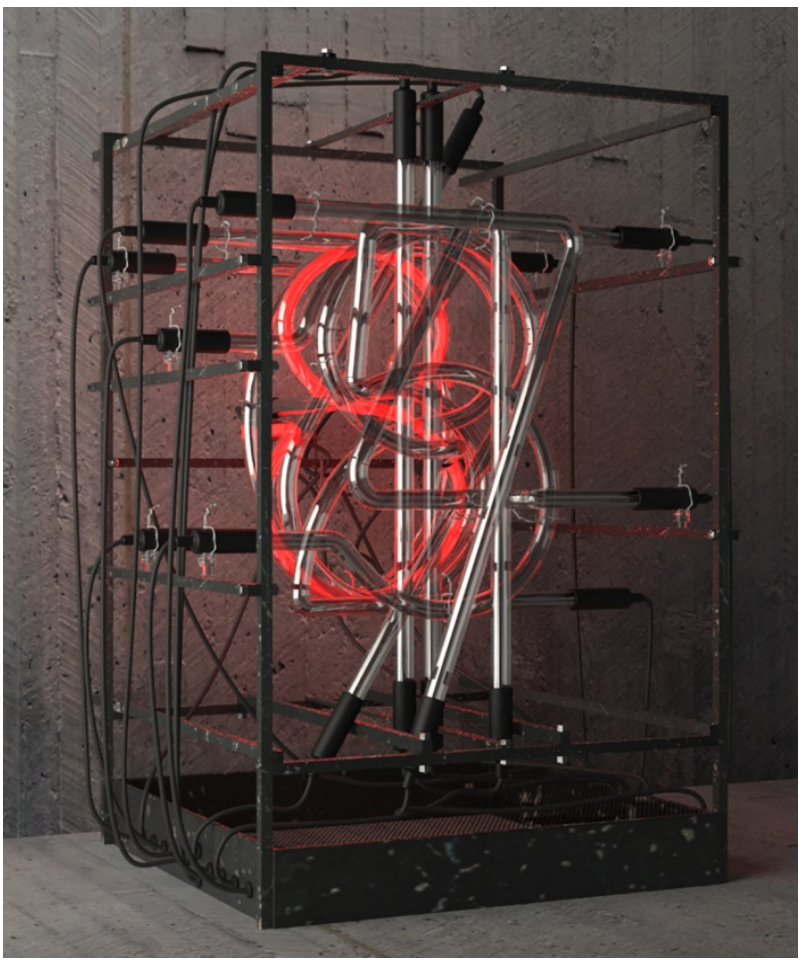

Figure 9: CAD renders of nixie digit in cage () Rachel Ara 2017

\subsection{Endorsers}

The endorsers have remained fundamentally the same as they share the same moral values. The difference is there is a different initial starting price as this larger work has been more costly to build. My time has hardly been factored in because artists working time is not valued.

\subsection{Editions}

During open studios last year, there was a lot of interest in my working drawings for the full scale work of This Much I'm Worth so I decided that the full artwork would produce a daily edition of 1 showing its current price. These are now selling on my website and is a source of funding.

\section{SUMMARY NOTES AND CONCLUSION}

In this paper l've shown where my concerns lie and how these are integrated into the making of an artwork. For me the making process and concerns are inseparable and resonate throughout the work.
Making art is not a science it's a process that evolves through the interaction of the artist with the work.

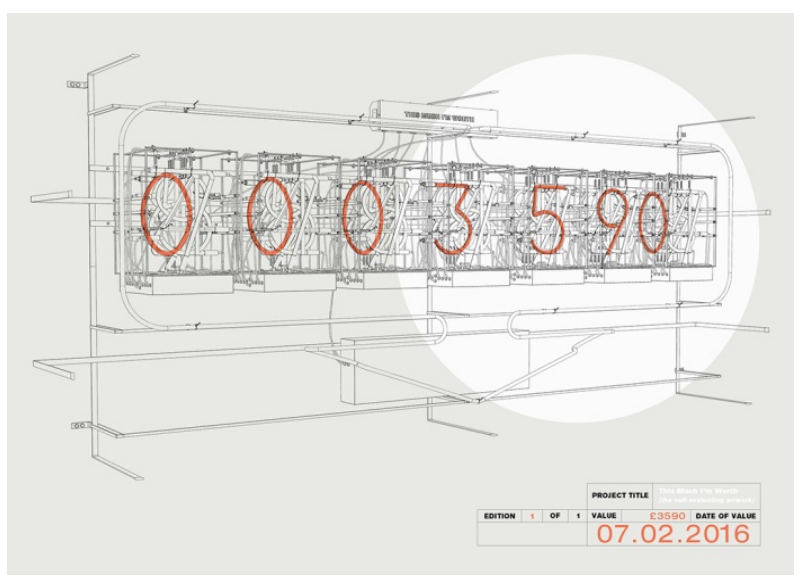

Figure 10: Daily value edition print produced by This Much I'm Worth (c) Rachel Ara 2016

Although new technologies are part of my background, the digital art world is new to me. I have begun noticing that where many of the artworks incorporate technology the artists have deferred to technicians to build or construct. We will never know how the work would have evolved or resonate had the artist done the making.

Technologies need to be investigated and critiqued thoroughly if artists are to fulfil what I believe is their responsibility.

I worry about the application VR / AR technologies where advances are being made via R\&D from the arms trade and porn industry. Where complex coding is being used in investment banking to hide money.

As Joy Buolamwini says in her TED Talk How I'm fighting the bias in algorithms (Buolamwini 2016):

- Who codes matters.

- How we code matters.

- Why we code matters.

We need a more inclusive practice within the world and within the art world. We need to see and hear a more diverse range of voices.

If you feel you have been adversely affected by any of the algorithms in this paper, please contact the Algorithmic Justice League which can be found online (http://www.ajlunited.org).

Live feeds of developments on this project can be seen on Instagram using the tag \#thismuchimworth 


\section{REFERENCES}

Artists Website (2017), www.2ra.co

Buolamwini, J, TED Talk (2016), How I'm Fighting bias in Algorithms.

https://www.ted.com/talks/joy buolamwini ho w i $\mathrm{m}$ fighting bias in algorithms/transcript? anguage $=e n$ (retrieved April 8 2017)

Daily Telegraph (2015)

http://theconversation.com/official-statisticsmask-extent-of-domestic-violence-in-the-uk$\underline{4087}$ (retrieved April 8 2017)

Financial Times (2017)

https://www.ft.com/content/907b4d2c-0ff0-11e7-

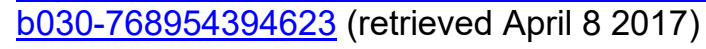

Guerrilla Girls (2017) https://www.guerrillagirls.com (retrieved April 8 2017)

Kosmaoglou, S. (2017) Aesthetica Anthology. Interview with Dr Sophia Kosmaoglou and Rachel Ara.

National Network to End Domestic Violence (2017) http://nnedv.org/getinvolved/dvam/1307-dvam-blogseries-1.html

(retrieved April 8 2017)

Refuge (2017)

http://www.refuge.org.uk/get-help-now/what-isdomestic-violence/domestic-violence-the-facts/ (retrieved April 8 2017).

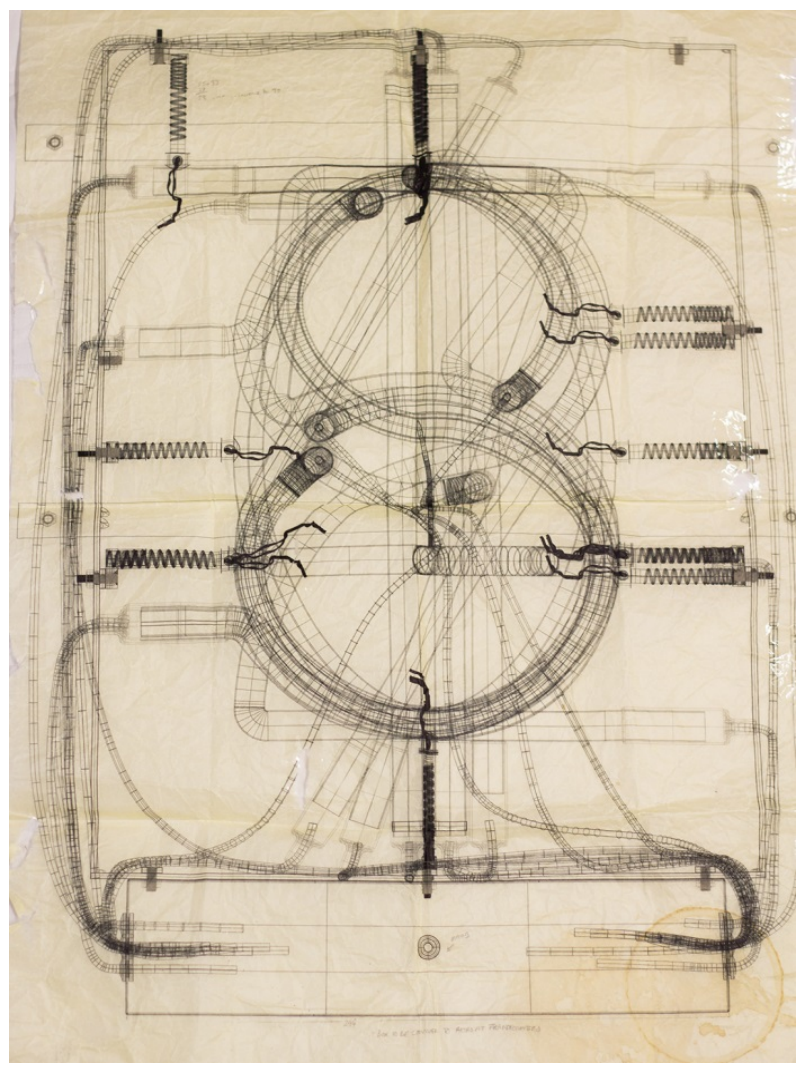

Figure 11: A Working Drawing, CAD drawing on canary paper (C) Rachel Ara 2015

On Display at the Royal West Academy Drawn Drawing Biennial, April - June 2017 